\title{
2-METHYL-6-PHYTYLQUINOL AND 2,3-DIMETHYL-5- PHYTYLQUINOL AS PRECURSORS OF TOCOPHEROL SYNTHESIS IN SPINACH CHLOROPLASTS
}

\author{
Jürgen Soll* and Gernot Schultz†
}

*Institut für Klinische Biochemie und Physiologische Chemie, Medizinische Hochschule Hannover and †Institut für Tierernährung, Arbeitsgruppe für Phytochemie und Futtermittelkunde, Tierärztliche Hochschule Hannover, D 3000 Hannover 1 , West Germany

(Revised received 23 May 1979)

Key Word Index-Spinacia oleracea; Chenopodiaceae; tocopherol biosynthesis; 2-methyl-6-phytylquinol; 2,3-dimethyl-phytylquinol; phytylquinol synthesis.

\begin{abstract}
The incorporation of $\left[\mathrm{Me}-{ }^{14} \mathrm{C}\right]$ from SAM- $\left[\mathrm{Me}-{ }^{14} \mathrm{C}\right]$ into precursors indicates the following sequence of tocopherol synthesis in spinach: 2-methyl-6-phytylquinol (6-phytyltoluquinol) (1a) $\rightarrow$ 2,3-dimethyl-5phytylquinol (phytylplastoquinol) (2a) $\rightarrow \gamma$-tocopherol (5a) $\rightarrow \alpha$-tocopherol (6). 1a is particularly preferred to 2 methyl-5-phytylquinol (1b) and 2-methyl-3-phytylquinol (1c). 1a only forms $2 a$. $2 a$ is converted to 6 via 5 and, to a lesser extent, 2,5-dimethyl-6-phylquinol (2b) to 6 via $\beta$-tocopherol (5b). Trimethylphytylquinol (3) is not an intermediate in the formation of 6 . All reactions are independent of light.
\end{abstract}

\section{INTRODUCTION}

Threlfall in $1971[1,2]$ proposed two equally plausible pathways for the biosynthesis of tocopherols. Thus the methylation might occur on the chromanol stage $(1 a \rightarrow 4 \rightarrow 5 a \rightarrow 6$ [1]) or on the phytylquinol and chromanol stage $(1 a \rightarrow 2 a \rightarrow 5 a \rightarrow 6$ [2]). In contrast, Janiszowska and Pennock in 1976 [3] concluded from their studies on whole plants of Phaseolus and Tropaeolum that methylation might occur more or less unspecifically yielding all isomers of phytylquinols and tocopherols. The paper presented here describes studies on tocopherol synthesis in spinach chloroplasts. The results essentially confirm the hypothesis in ref. [2].

\section{RESULTS}

Optimization for tocopherol synthesis in chloroplasts. The need for SAM instead of methionine plus ATP

Only chloroplasts of non-differentiated leaves (1-2 weeks old) are capable of tocopherol synthesis. In these optimization experiments using very young leaves no substrate was added because the leaves contain relatively large amounts of prenylquinols as endogenous substrates (on average $1 \mathrm{nmol} 2 \mathrm{a}$ and nmol 1a per $\mathrm{mg}$ chlorophyll). No $C$-methylation occurs if Met + ATP instead of SAM is applied. Obviously chloroplasts are not able to form SAM under these conditions. Chloroplasts osmotically shocked for a few minutes (in suspensions with more than $1 \mathrm{mg}$ chlorophyll $/ \mathrm{ml}$ ) show nearly the same rates as more or less intact ones (suspensions with $60-80 \%$ intact chloroplasts). Optimal rates are found at pH 7.6 in

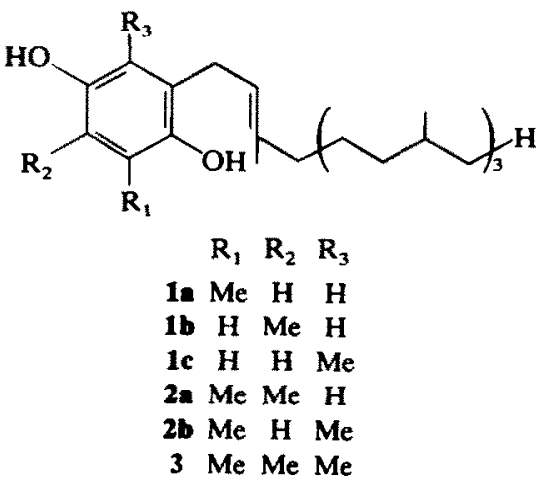<smiles>[R]c1c(C)c2c(c([R])c1O)CCC(C)(CCCC(C)CC([2H])C)O2</smiles>

medium $C$ according to Jensen and Bassham [4] containing $10 \mathrm{mM} \mathrm{NaHCO}_{3}$. At pH 6.7 the rate is $85 \%$, and at $\mathrm{pH} 6.155 \%$ of the optimum.

$6-\left[{ }^{14} \mathrm{C}\right]$ formed by the reaction with $\mathrm{SAM}-\left[\mathrm{Me}-{ }^{14} \mathrm{C}\right]$ in chloroplasts was examined for constancy of specific activity (sp. act. (dpm $/ \mathrm{nmol}$ ) after the addition of carrier-6: 1 st TLC on system II 9.84; 2 nd TLC on system IV $9.32 ; 3$ rd TLC on system III 8.48). 
Steps of biosynthesis

The incorporation of $\left[\mathrm{Me}-{ }^{14} \mathrm{C}\right]$ from SAM- $\left[\mathrm{Me}^{-14} \mathrm{C}\right]$ into 1a yields labelled $2 a$ and the quinone of $2 \mathbf{a}, 5 a$ and 6 in decreasing amounts (Table 1). Among the possible isomers of dimethyl compounds only 5a could be detected after the formation of nitroso-derivatives (see Experimental). This indicates that only the 2,3dimethyl compounds are formed from 1s.

Furthermore, $\left[\mathrm{Me}^{14} \mathrm{C}\right]$ from SAM- $\left[\mathrm{Me}^{14} \mathrm{C}\right]$ is incorporated into 2 yielding $6-\left[{ }^{14} \mathrm{C}\right]$ (Table 1). Intermediate formation of 3 could be detected neither with 2a nor with 1a as substrate (Fig. 1). It was not possible to show the predictable formation of $5 \mathbf{a}$ by the cyclization of $2 \mathrm{a}$ in experiments with SAM- $\left[\mathrm{Me}-{ }^{14} \mathrm{C}\right]$, but it may be deduced undoubtedly from the following experiments. $5 \pi-\left[{ }^{14} \mathrm{C}\right]$ was produced in experiments with 1. and SAM- $\left[\mathrm{Me}-{ }^{14} \mathrm{C}\right]$ in amounts much larger than in experiments with 4 and SAM $-\left[\mathrm{Me}^{14} \mathrm{C}\right]$ (Table 1 ). Moreover, $C$-methylation of $5 a$ yielding $6-\left[{ }^{14} \mathrm{C}\right]$ was a reliable reaction for the standardization in the experiments in Table 1.

The $C$-methylation is strictly enzymic; if chloroplasts were omitted, no reaction occurred. Activity with endogenous substrates was negligible in ca 2-week-old leaves used here. Hence the following sequence in tocopherol synthesis can be derived: $1 \mathbf{a} \rightarrow \mathbf{2 a} \rightarrow \mathbf{5} \rightarrow \rightarrow$ $6(2 a \# 3)$. Considering the results mentioned above the other possible sequence $1: \rightarrow 4 \rightarrow 5 n \rightarrow 6$ is only an unspecific pathway in spinach.

\section{Substrate specificity}

In spinach the pathway outlined above seems to be fairly specific. In the first step in is the favoured substrate for the incorporation of a methyl group from SAM; the isomers $1 \mathrm{~b}$ and $1 \mathrm{c}$ are both converted at
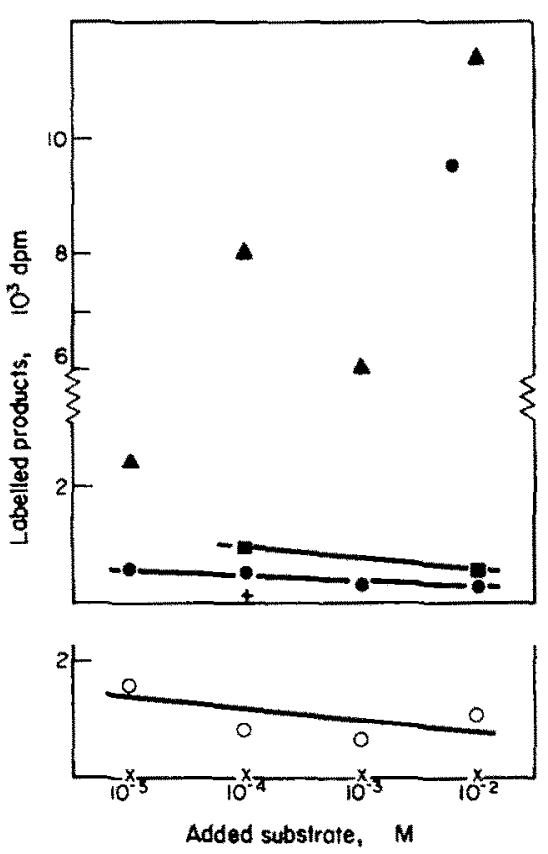

Fig. 1. ${ }^{14} \mathrm{C}$-Incorporation from SAM-[Me- $\left.{ }^{14} \mathrm{C}\right]$ into substrates of different concentrations: upper diagram-products from 10 as substrate: 2a $(\Delta), 3(+), 5 a(1), 6(O)$; lower diagram-products from $2 \times$ as substrate: $3(x) ; 6(0)$.

very low rates $\left({ }^{14} \mathrm{C}\right.$-labels in corresponding dimethyl compounds $100: 10: 5$ ). For the second step the substrate of cyclization is $2 \mathbf{a}$ and also $2 \mathbf{b}$; both are cyclized and methylated to 6 at comparable rates. In the third step $5 \mathrm{a}$ is preferred to $5 b$ in the synthesis of 6 $\left({ }^{14} \mathrm{C}\right.$-labels in 6 100:37).

Table $1 .{ }^{14} \mathrm{C}$-Incorporation from SAM-[Me- $\left.{ }^{14} \mathrm{C}\right]$ into substrates of tocopherol synthesis in chloroplasts suspensions

\begin{tabular}{|c|c|c|}
\hline Substrate* & Product & $\begin{array}{c}{ }^{14} \mathrm{C} \text {-Incorporation in } \\
\left.\% \text { of added SAM-[Me- }{ }^{14} \mathrm{C}\right]\end{array}$ \\
\hline \multirow[t]{4}{*}{$+1 \mathbf{a}$} & $2 \pi$ & 1.500 \\
\hline & Quinone of $2 a t$ & 0.545 \\
\hline & 5a & 0.628 \\
\hline & 6 & 0.250 \\
\hline \multirow[t]{4}{*}{ +Quinone of 1a } & $2 a$ & 0.005 \\
\hline & Quinone of $2 n^{+}$ & 0.570 \\
\hline & 5 & 0.310 \\
\hline & 6 & 0.033 \\
\hline \multirow[t]{4}{*}{+4} & 2ał & 0.029 \\
\hline & Quinone of 2at+ & 0.068 \\
\hline & 5a & 0.072 \\
\hline & 6 & 0.019 \\
\hline$+2 n$ & 6 & 0.107 \\
\hline + Ouinone of $2 a$ & $6 \ddagger$ & 0.003 \\
\hline \multirow[t]{4}{*}{+5} & 2ut & 0.005 \\
\hline & Quinone of $2 n t \ddagger$ & 0.007 \\
\hline & 5 ał & 0.026 \\
\hline & 6 & 0.230 \\
\hline
\end{tabular}

${ }^{*} 2 \times 10^{-3}$, light, for further details see Experimental.

tFormed partially by oxidation during isolation procedure.

\#Formed presumably by methylation of endogenous substrates by SAM$\left[\mathrm{Me}^{14} \mathrm{C}\right]$. 


\section{Quinones instead of quinols as substrates}

In any case quinones are methylated by SAM less well than the corresponding quinols. The quinone of 1a was converted, at low rates, to the quinone of $2 a$, $5 a, 6$ and tracers of $2 a$. The quinone of $2 a$ as a substrate, however, was converted to 6 in negligible amounts (Table 1).

\section{Rates in the light compared to those in the dark}

None of the steps show a significant difference between light and dark. As the quinol stage is better preserved in the dark, the rate of methylation seems somewhat higher in the dark than in the light.

\section{Effect of substrate concentration}

Using 1a or $2 \mathrm{a}$ as substrate at a concentration of $10^{-5} ; 10^{-4}, 10^{-3}$ and $10^{-2} \mathrm{M}$, the optimal substrate concentrations were tested. These are $c a 10^{-2} \mathrm{M}$ in for the formation of $2 a, 10^{-4}-10^{-3} \mathrm{M}$ 1a for $5 \mathrm{a}$, and $10^{-4}-10^{-5} \mathrm{M} 2 \mathrm{a}$ for the formation of 6 (Fig. 1).

\section{DISCUSSION}

Phytylquinols serve as precursors in the biosynthesis of tocopherols. Firstly, the electrophilic substitution by SAM requires a substance present in the reduced stage. Secondly, a quinol structure is a prerequisite in the formation of the chromanol ring. In our experiments quinones seem to be reduced by factors formed during photosynthesis. One problem is why the two methylation steps take place at different stages, the first one at the phytylquinol stage yielding $2 \mathbf{a}$ from 1a, and the second one at the tocopherol stage yielding 6 from 5a. Presumably this is caused by different compartmentation of the enzymes responsible for the methyl transfer at the monomethyl or dimethyl stage.

As demonstrated by Janiszowska and Pennock [3], the corresponding methyltransferases exhibit no substrate specifity in Phaseolus. Through isomers of dimethylphytylquinols and to a very small extent, ot monomethylphytylquinols react with SAM, the pathway is channelled of the methylphytylquinol stage in spinach: firstly, only the 6-isomer is formed from homogentisate and prenyl-PP (Threlfall, D. R., personal communication) and, secondly, this isomer is the particularly favoured substrate in the methylation reaction yielding the 2,3-dimethyl compound $2 \mathrm{a}$. From there, the pathway is directed to $5 n$ and 6 . Modifications may be supposed only in species containing $\mathbf{5 b}$ and 5a, e.g. Hordeum, Avena, Triticum, etc. [5]. Furthermore the fact that $5 \mathbf{a}$ is temporally preferred to 6 in time course studies on maize and lettuce (Schultz and Keppler, unpublished results) might be deduced from its sequence in synthesis and is not a regulation phenomenon (Fig. 2).

Since the side reaction from 1a to 4 seems to be absent in spinach and the reaction of to $5 \mathrm{a}$ is only poor, the absence of 4 is explicable. Likewise in Hedera [6], Hevea $[7,8]$ and Ficus [9], 4 seems to be a product of a side reaction $[1,2,6]$ rather than an intermediate in the formation of dimethyl and trimethyl tocopherols [8].

Though the above 'tocopherol pathway' [3] generally occurs in higher plants, it might be somewhat modified, especially in species containing tocotrienols

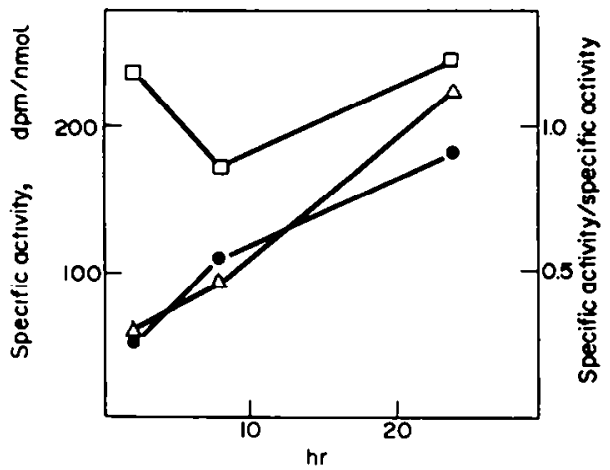

Fig.2. Time course of ${ }^{14} \mathrm{C}$-incorporation from tyrosine-[ $\beta$ $\left.{ }^{14} \mathrm{C}\right]$ in $5 \mathrm{and} 6$ of illuminated maize shoots. The sp. act. of Sa( $(\square)$ and $6(\Delta)$, respectively, and the ratio of sp. act. of $6 / \mathrm{sp}$. act. of $\operatorname{Sa}(0)$ are shown.

[5, 7-9]. In Hevea [7, 8] and Ficus [9] they are formed in tissues different from leaves. There the 'tocotrienol pathway' [3] is localized in the latex whereas the 'tocopherol pathway' is more or less restricted to the leaves [8]. Moreover, in Hevea a portion of tocotrienols is esterified with palmitate [5]. The hydrogenation of tocotrienols may be a principal reaction for converting them into tocopherols as was inferred from the incorporation of tritium from ' $A$ ' tritio-NADPH(4R-diastereoisomer) into tocopherols in Ficus [9] or it may be a side reaction from $\alpha$-tocopherol to 6 as in Hevea latex $[3,8]$.

\section{EXPERIENTAL}

Radiochemicals. SAM-[Me- $\left.{ }^{14} \mathrm{C}\right]$ (sp. act. $59 \mathrm{mCi} / \mathrm{mmol}$ ) and methionine-[Me- ${ }^{14} \mathrm{C}$ ] [sp. act. $60 \mathrm{mCi} / \mathrm{mmol}$ ] were obtained from Amersham-Buchler, Braunschweig; tyrosine-[ $\beta$ $\left.{ }^{14} \mathrm{C}\right]$ was purchased from NEN, Dreieichenhain and later from CIS, Gif-sur-Yvette, France.

Synthesis of cis, trans 2,3-dimethyl-5-phytyl-1,4benzoquinone (2,5-cyclohexadiene-1,4-dione-2,3-dimethyl-5(3, 7, 11, 15-tetramethyl-2-hexadecenyl) (quinone of 2a) [10]. All methyl quinones were prepared from the phenols by use of Fremy's salt $[11,12]$ and reduced according to ref. [13]. Freshly distilled $\mathrm{BF}_{3}$-etherate $(0.3 \mathrm{ml}$ in $1 \mathrm{ml} \mathrm{THF})$ was added drop by drop by syringe to a soln of $150 \mathrm{mg} \mathrm{2,3-}$ dimethylquinol, $200 \mathrm{mg} \mathrm{Al} \mathrm{O}_{3}$ and $300 \mathrm{mg}$ isophytol in $2 \mathrm{ml}$ dry THF. The mixture was stirred for $15 \mathrm{hr}\left(\mathrm{N}_{2}\right.$, dark). The substance was hydrolysed with ice, extracted with $\mathrm{Et}_{2} \mathrm{O}$ and dried. The $\mathrm{Et}_{2} \mathrm{O}$ phase was evapd. The resulting 2a [13] was oxidized by $\mathrm{Ag}_{2} \mathrm{O}(400 \mathrm{mg})$ in dry $\mathrm{Et}_{2} \mathrm{O}$. Purification was affected by column chromatography (Si gel (Merck 60); system I). MS $\left(20^{\circ}\right): \mathbf{M}^{+} \mathrm{m} / \mathrm{e}: 414(50 \%), 189(100), 151(50)$, 63.5 (54.5), 62 (40.9), 44 (68.8), 42 (52.2). IR cm ${ }^{-1}$ : alkyl-H 2950, 2925, 2867; $\mathrm{C}=\mathrm{O} 1649 ; \mathrm{C}=\mathrm{C} 1615$. 'H NMR $\left(60 \mathrm{MHz}, \mathrm{CDCl}_{3}\right): \delta 0.91(12 \mathrm{H}, \mathrm{Me}$ chain); $1.23(19 \mathrm{H}$, chain); $1.62(3 \mathrm{H}, \mathrm{C}=\mathrm{C}-\mathrm{Me}) ; 2.01\left(2 \mathrm{H}, \mathrm{CH}_{2}\right.$-allyl to $\mathrm{C}=\mathrm{C}$ chain); $2.04(6 \mathrm{H}, \mathrm{Me}$ quinone $) ; 3.1\left(2 \mathrm{H}, \mathrm{CH}_{2}\right.$-allyl to $\mathrm{C}=\mathrm{C}$ quinone and chain $) ; 5.1(1 \mathrm{H}, \mathrm{HC}=\mathrm{C}$-chain $) ; 6.5(1 \mathrm{H}$, quinone).

Synthesis of cis, trans 2,5-dimethyl-6-phytyl-1,4benzoquinone (quinone of $2 \mathbf{b}$ ) was according to above procedure except that 2,5-dimethyl quinol $[11,12]$ was used.

Synthesis of cis, trans-2-methylphytyl-1,4-benzoquinones 
(2,5-cyclohexadiene-1,4-diones-2-methyl-(3, 7, 11, 15-tetramethyl-2-hexadecenyl) (quinones of 1a, 1b and 1c). Synthesis was carried out by the procedure described above. The fractionation of the isomer mixture was made by multiple TLC on system I (see [3]).

Reduction of phytylquinones for studies on chloroplasts. A photometrically adjusted amount of quinone (for extinction coefficients compare [14]) was dissolved in $1 \mathrm{ml} \mathrm{MeOH,}$ reduced with solid $\mathrm{NaBH}_{4}$ for $2 \mathrm{~min}$, transferred to $\mathrm{Et}_{2} \mathrm{O}$ and washed with $\mathrm{H}_{2} \mathrm{O}$. The $\mathrm{Et}_{2} \mathrm{O}$ phase was evapd to dryness under $\mathrm{N}_{2}$ in vials $(10 \times 1 \mathrm{~cm})$ and could be stored at $-20^{\circ}$ in the dark for 1 to $2 \mathrm{hr}$.

Chloroplasts were isolated from spinach according to ref. [4] but in a modified way as described in ref. [15]. The percentage of intact chloroplasts was determined by the Hill reaction [16].

Broken chloroplasts were prepared as above except that the chloroplast pellet centrifuged in Medium $B$ [4] was suspended in $\mathrm{H}_{2} \mathrm{O}$ until a chlorophyll content of $c a 2 \mathrm{mg} / \mathrm{ml}$ was obtained.

Application of substrates for tocopherol synthesis in chloroplasts. The following substances were added to the vials $(10 \times 1 \mathrm{~cm})$ containing the substrate $\left(10^{-5}-10^{-8} \mathrm{~mol}\right.$ suspended in $20 \mu \mathrm{I} \mathrm{EtOH}$ ): $50 \mu \mathrm{l} 0.2 \mathrm{M} \mathrm{NaHCO}_{3}, 2.5 \mu \mathrm{Ci}$ SAM $\left(=50 \mu \mathrm{l}\right.$ soln in $\left.0.1 \mathrm{~N} \mathrm{H}_{2} \mathrm{SO}_{4}\right)$ and $1 \mathrm{ml}$ chloroplast suspension in Medium $\mathrm{C}, \mathrm{pH} 7.6$ (at least $1 \mathrm{mg}$ chlorophyll $/ \mathrm{ml}$ ). The suspension was illuminated by halogen lamps $\left(0.1 \mathrm{~J} / \mathrm{cm}^{2} \mathrm{sec}\right)$ and stirred slowly at $20 \pm 2^{\circ}$ for $30 \mathrm{~min}$. For broken chloroplasts, however, $0.5 \mathrm{ml}$ of chloroplast suspension in $\mathrm{H}_{2} \mathrm{O}$ (containing at least $2 \mathrm{mg}$ chlorophyll $/ \mathrm{ml}$ ) plus $0.5 \mathrm{ml}$ Medium $\mathrm{C}, \mathrm{pH} 7.6$ [4] were used. In the methionine-[Me- $\left.{ }^{14} \mathrm{C}\right]$ expt., $4 \mu \mathrm{Ci}(\mathrm{ca} 0.1 \mu \mathrm{mol})$ methionine[Me- ${ }^{14} \mathrm{C}$ ] plus $2 \mu \mathrm{mol}$ ATP were used. Where rates are cited in Results, the data are from expts performed with the same chloroplast suspension.

Application of tyrosine $-\left[\beta^{-14} \mathrm{C}\right]$ to maize shoots. Tyrosine$\left[\beta-{ }^{14} \mathrm{C}\right](0.5 \mu \mathrm{Ci})$ in $50 \mu l 0.01 \mathrm{~N} \mathrm{NaHCO}_{3}$ was added to excised maize seedlings (in the primary leaf stage) inserted into small vessels in couples. 10 seedlings per time interval were used. They were illuminated by white light bulbs $(3 \mathbf{k l x})$ and $\mathrm{H}_{2} \mathrm{O}$ was added in $50 \mu \mathrm{l}$ portions if needed.

$T L C$ systems. System I-Si gel with petrol (bp 60-80')$\mathrm{Et}_{2} \mathrm{O}, 15: 1$; system II-the same but $10: 1$; system III-Si gel with $\mathrm{C}_{6} \mathrm{H}_{6}-\mathrm{CHCl}_{3}, 1: 1$; system IV-reversed-phase system (cellulose impregnated with $7 \%$ paraffin oil in petrol, bp $100-140^{\circ}$ ) with $\mathrm{Me}_{2} \mathrm{CO}-\mathrm{MeOH}, 2: 1$; system $\mathrm{V}$-the same with $\mathrm{Me}_{2} \mathrm{CO}-\mathrm{H}_{2} \mathrm{O}, 85: 15$; system VI-the same with $96 \% \mathrm{EtOH}$ (all layers with fluorescent indicator F 254 on glass (Schleicher \& Schüll)).

Isolation of phytylquinones, tocopherols and other isoprenoids from chloroplast suspensions. $\mathrm{Me}_{2} \mathrm{CO}(30 \mathrm{ml})$ and $60 \mathrm{ml}$ petrol (bp $40-60^{\circ}$ ) were added to a separatory funnel containing the treated chloroplast suspension. Carriers were provided at a range of $50-100 \mu \mathrm{g}$ each. $\mathrm{H}_{2} \mathrm{O}(500 \mathrm{ml} \times 2)$ was continuously added without shaking. After discharging the water phase carefully, the petrol phase was evapd to dryness under $\mathrm{N}_{2}$. The residue was dissolved in a minimum of $\mathrm{Me}_{2} \mathrm{CO}$ and chromatographed by system II. Usually the quinols were oxidized by an air supply before TLC. After recovering the substances from system II they were applied to system V. All substances were characterized by co- chromatography with markers.

In system II the sequence of substances in the prenylhydroquinone plus tocopherol zone is (beginning with the orgin of chromatogram up to $R_{f} c a 0.25$ ): 1a and isomers, plastoquinol, 2a and isomers, 3, $4,5 a+5 b, 6$ (all substances are detectable with the Emmery-Engel reagent). For the polyprenylquinone zone the sequence is (beginning from $\boldsymbol{R}_{f}$ ca 0.7 to ca 0.9 ): quinone of $1 \mathrm{a}$ and isomers, phylloquinone, plastoquinone, quinone of $2 a$ and isomers, quinone of 3 (all quinones) are detecable by quenching fluorescence at $254 \mathrm{~nm}$ ). In system $V$ the sequence is: lower partplastoquinone, quinone of 3 , quinone of $2 \mathrm{a}$ and isomers, quinone of $1 a$ and isomers; middle part $-6,5 a+5 b$; upper part-plastoquinol, 3, 2a and isomers, 19 and isomers.

Nitroso-derivatives of $\mathbf{5 a}$ and $\mathbf{5 b}$ were formed according to ref. [17]. NO-5a $\left(R_{f} c a 0.2\right)$ was separated from NO-5b $\left(R_{f}\right.$ ca 0.4$)$ in system VI.

Acknowledgements-Financial support by the Deutsche Forschungsgemeinschaft is thankfully acknowledged. We are gratefully indebted to Drs. U. Gloor, R. Rüegg and F. Weber, Fa. Hoftmann-La Roche \& Co. Ltd., Basel, for reference substances of phytylquinones and tocopherols; Prof. Dr. H. Krug, Institut für Gemüsebau, Universität Hannover, for plant material and Mrs. Doris Bodenstab for excellent technical assistance.

\section{REFERENCES}

1. Threlfall, D. R. and Whistance, G. R. (1971) in Aspects of Terpenoid Chemistry and Biochemistry (Goodwin, $\mathrm{T}$. W., ed.) pp. 335.-404. Academic Press, London.

2. Threlfall, D. R. (1971) Vitam. Horm. 29, 153.

3. Janiszowska, W. and Pennock, J. F. (1976) Vitam. Horm. 34, 77.

4. Jensen, R. G. and Bassham, J. A. (1966) Proc. Natl. Acad. Sci. U. S. A. 56, 1095.

5. Chow, C. K., Draper, H. H. and Csallany, A. S. (1969) Analyr. Biochem. 32, 81.

6. Whistance, G. R. and Threlfall, D. R. (1968) Biochem. J. 109,577

7. Whittle, K. J., Audley, B. G. and Pennock, J. F. (1967) Biochem. J. 103, $21 \mathrm{c}$.

8. Peake, I. R., Audley, B. G. and Pennock, J. F. (1970) Biochem. J. 119, $58 \mathrm{p}$.

9. Wellburn, A. R. (1970) Phytochemistry. 9, 743.

10. Soll, J. (1978) Diplom examination paper, University of Hannover.

11. Teuber, H. J. and Rau, W. (1953) Chem. Ber. 86, 1036.

12. Zimmer, H., Lankin, D. C. and Hargan, S. W. (1971) Chem. Rev. 71, 231.

13. Mayer, HI. and Isler, O. (1971) in Methods in Enzymology (Colowick, S. P. and Kaplan, N. O., eds.) Vol. 18 c, pp. 241-348. Academic Press, New York.

14. Threlfall, D. R. and Goodwin, T. W. (1967) Biochem. J. $103,573$.

15. Bickel, H. (1979) Thesis, University of Hannover.

16. Heber, U. and Santarius, K. A. (1970) Z. Naturforsch. 256, 718.

17. Marcinkiewicz, S. and Green, J. (1959) Analyst 84, 304. 